\title{
Grice's Maxims: Investigate the Intent of the Infringements in "The Prince and the Pauper" Conversational Discourse
}

\author{
Maya Yolanda \\ Universitas Lancang Kuning, Pekanbaru, Indonesia \\ mayayolanda2805@gmail.com
}

\author{
ARTICLE HISTORY \\ Received : 2020-01-16 \\ Revised : 2020-03-27 \\ Accepted : 2020-03-31
}

\section{KEYWORDS}

Grice's Maxim

The Prince and the Pauper Movie

\begin{abstract}
Grice coins 4 maxims to govern daily conversation as a general rule. The maxims are Quantity, Performance, Value and Manner. On this basis, the author intends to address the breaches of Grice's maxims in one selected film and to investigate the intent of the infringements in "the Prince and the Pauper" conversational discourse. Many sections of the film contain violations of Grice's maxim characters. The writer formulates two work problems in order to achieve these goals: Which of Grice's maxims was violated in The Prince and the Pauper movie by the addressees?; For what reasons are the maxims infringed by the addresses?. Based on the analysis, the author argues that the characters, in particular Duke, Tom Canty, King, and the Earl of Hertford, have violated Grice's four maxims in the film dialogue. If they fail to provide sufficient information, tell their addressees to lie, provide irrelevant glosses, and fail to be real, concise, univocal, and orderly, they violate the Quantity, Value, Relevance, and Manner maxims, respectively. In reality, the writer believes that characters are breaching the maxims to trick colleagues, to be sweet, to save face, to avoid discussion, and to show self-interest.
\end{abstract}

\section{Introduction}

In this article, we briefly present O\&R's theory; then look at how it was interpreted immediately after its publication and, more precisely, look at some of the criticisms made at the time - especially by Wittgenstein (1889-1951) (O\&R initially claimed that their book was an answer to some of Wittgenstein's philosophical problems in the Tractatus, where the philosopher asked important theoretical questions). In the last section we see how some of the paradoxes resulting from O\&R's theory are still alive today, particularly for the computational linguistics community.

Richards contends that representations are exceptionally viable in encouraging cognizance and along these lines limiting false impressions. Richards depicts allegory as "the utilization of one reference to a gathering of things between which a given connection holds, to encourage the separation of a similar to connection in another gathering. In the comprehension of allegorical language one reference gets some portion of the setting of another in a unique structure." Since illustration uncovers the connection between two divergent items, it is compelling in conveying encounters to others since the speaker may utilize the audience's information on one of the articles to grant the importance of the second. In talking about similitudes, Richards utilizes two terms- "tenor" and "vehicle." The tenor alludes to the hidden thought or chief subject of the illustration. The vehicle passes on the hidden thought, the acquired thought, or what the tenor looks like.
For instance, in "The sun is a red inflatable," the tenor is the sun and the vehicle is the inflatable (i.e., qualities of redness and roundness are being credited to the sun). The triangle of reference (otherwise called the triangle of meaning and the semiotic triangle) is a model of how phonetic images are identified with the items they speak to.

The triangle was distributed in The Importance of Significance (1923) by Ogden and Richards. While frequently alluded to as the "Ogden/Richards triangle" the thought is likewise communicated in 1810 , by Bernard Bolzano, in his Beiträge zu einer begründeteren Darstellung der Mathematik. Notwithstanding, the triangle can be followed back to the fourth century BC, in Aristotle's Peri Hermeneias (frequently alluded to in its Latin interpretation De Interpretatione, second book of his Organon). The Triangle identifies with the issue of universals, a philosophical discussion which split antiquated and medieval thinkers (for the most part pragmatists and nominalists).

\section{Method}

Qualitive descriptive used in this study also aims underlie the contemporary reflection on the present circumstance, since the hypothesis is very good old. This examination uncovers the hypothesis still fit with contemporary circumstance under two focal point: 1) the presumption that significance and utilization of language are significant and 2) the intrigue/requirement for semantic natives viewed as a lot of essential units which can be utilized as Interlingua. 


\section{Result and Discussion}

\subsection{Ogden and Richards Theory Abridged}

People believe from the O\&R theory that words have a different, precise meaning that they think is wrong. This mistake leads to comprehension. The authors then suggest that to improve the understanding of people, we need to solve these problems.

The main focus of the book is on words. Words are regarded as symbols conventionally representing world objects (the referent). The perception of the object in the brain (the reference) allows the connection between a word and an entity. Significance therefore depends on the relationship between the term (symbol), the picture in the brain (reference) and the object in the world the main focus of the book is on words.

Words are known as signs conventionally representing world entities (the referent). The object's perception in the brain (the reference) permits the connection between a word and an entity. Significance therefore depends on the relationship between the word (symbol), the brain picture (reference) and the object of the term. Note that this semiotic triangle is not new and was not introduced by $O \& R$ in the beginning. Comparable ideas are already present in the works of Charles Pierce (18391914), for example; this is clearly mentioned as such in the appendix to the book of O\&R (p. 279). However, O\&R popularized the semiotic triangle.

However, the semiotic triangle was popularized by O\&R. The book will be widely studied in universities that speak English. It is still widely used and accepted as such, e.g. in departments of communication. According to O\&R, people believe that every word has a precise, correct meaning. But in reality, meaning is largely driven by personal experience (words, based on past experience, evoke different things or feelings), so the same word means different things to different people.

In fact, because of personal experience which contributes to incomprehension, it is for O\&R that people use words in such or such a way. O\&R subsequently suggested a number of solutions to avoid misunderstandings. It is possible to reduce confusion by:

1) Have clear definitions (specify what is included in the meaning of the word);

2) Use of metaphors (i.e. Idiom for words or notions);

3) Use of ' feed forward ' (taking into consideration, as far as possible, the consumer's meaning and aspirations); and

4) Use of basic english (a simplified set of precise words used as primitives).
With regard to this last point, O\&R believes that a basic, controlled vocabulary can be defined insofar as human feelings are excluded from this basic vocabulary (Ogden, 1930). The reduced vocabulary can be interpreted as a set of basic words, and complex concepts can be explained by combining these primitives. As we will see later, the basic Artificial Intelligence Semantic community is a key component of any semantic research (in particular, interlingua machine translation, see Léon, 2007) which echoed this study.

\subsection{Reception of O\&R's work by Wittgenstein}

Wittgenstein was an O\&R close colleague in Cambridge. Ogden translated Wittgenstein's Tractatus Logico-Philosophicus in 1921-1922, which was primarily concerned with sense (it was, in fact, F. Ramsey (1903-1930), then Ogden's Cambridge student who did the work). One of W's book's key points (among many others) is to distinguish what can be said from what can't be said (logically and philosophically).

From this point of view, there are clearly echoes between the theory of $\mathrm{W}$. and the book of O\&R. Ogden believed that the Meaning of Meaning was a response that could solve the Tractatus problems. Owing to $\mathrm{W}$. Words refer to objects, communicate object-to-language relationships reflect the essence of the environment as well as O\&R. This requires a proper analysis of the relationships between the fundamental entities of the universe and a logical inference from these relationships.

In reality, both books have a therapeutic role. Wittgenstein wants to heal philosophy from false issues (problems that can not be solved by logical interpretations of basic facts, cf. religion, aesthetics) while O\&R wants to heal from misunderstandings experiences. Both of them are proposing solutions to this problem.

Because of the parallels between these works, Ogden assumed that the Meaning of Meaning was going some way towards providing a causal solution to the sense question as described in the Tractatus. Wittgenstein then felt compelled to give an evaluation of the text, and he replied bluntly that Ogden had not fully grasped the issues he had dealt with in the Tractatus (Wittgenstein, 1973-69). Several authors suggest the W, like Jerzy Perzanowski (1993). Defends a theoretical point of view radically different from that articulated by O\&R, even though Ogden did not see the argument in 1923. As Perzanowski explained, in the Tractatus, W. Sets a direct link between words and objects, thus defending direct reference.

For Wittgenstein, emotional language was definitely not a philosophical issue in 1923. Nonetheless, we should remember the so-called 
"second" W. (After returning to Cambridge in 1929), a very different theory will be established. The W's later. Defends the view that words are not specifically related to objects in the universe (and the language structure does not correspond directly to the structure of the world). Instead, the meaning of a word corresponds to its use, and context is highly relevant for meaning. In the Tractatus, Wittgenstein is only interested (and not in communication) in logic and philosophy. The Tractatus addresses only philosophy, but emotional language is not a topic discussed by Wittgenstein, nor does The Meaning of Language offer some new insight into Wittgenstein's philosophical problems.

\subsection{Why is The Meaning of Meaning still Influential Today?}

If one believes in the concept of O\&R, it seems possible to describe a language (or interlingua) made up of unambiguous meanings (i.e. linguistic primitives) if the emotional aspect of language is omitted. O\&R's book is the origins of two types of applications in this perspective:

1) Definition of a clear language for enhanced (human) interaction

2) Definition of a clear language for computer-based applications (especially for artificial intelligence).

As previously mentioned, Ogden himself established the Basic English in the 1930s. The aim of this project was to improve human communication by defining terms from unambiguous primitive sets. In addition to human communication, the issue of semantic primitives is a classic Artificial Intelligence (AI) issue, especially for Machine Translation.

The key point in this area is to describe the meanings of words (or phrases) in order to find the appropriate counterpart in the target language. We'll take a look at the CLRU (Cambridge Language Research Unit) to go ahead with a specific example.

The CLRU is particularly important among the numerous teams that were involved in machine translation: this group was a prototypical example of domain work in the 1950s. Founded in 1955 in Cambridge, UK, the CLRU was a small research unit that was involved in machine translation. It was directed by former Wittgenstein student Margaret Masterman (1910-1986). Masterman largely acknowledged her inspiration from Wittgenstein, but only from the second Wittgenstein (Masterman, 2005). She regularly mixed in Cambridge with scholars like Ivor A. Richards, the co-author of the Meaning of Meaning; following this tradition, she insisted on the importance of semantics rather than syntax for Machine Translation, which makes her approach highly original (see Léon, 2000). Many years before (in the 1930s and 1940s), as we saw in the previous section, many factors moved Wittgenstein back to theory, including the fact that literal meaning did not equate to meaning as such. W. then developed a complex philosophical investigation of language (Wittgenstein, 1953).

This investigation did not include O\&R's emotional language as such, but W. The concept of language games, i.e. the fact that context and circumstances have an effect on meaning, was introduced. The change is radical in comparison to the Tractatus, where the idea of direct reference, i.e. a direct correspondence between language and world, is defended. In the inquiries, W. He firmly supports a situation-based interpretation of context that had a significant influence on Masterman. The second $\mathrm{W}$, to be more precise. Defends the notion of use of language and game of language and emphasizes perceptions, feelings and situations. So from the point of view of $O \& R$, the second $W$. Philosophy, in a sense, incorporates the vocabulary of feeling. W., though. He made no reference to the concept of O\&R. In fact, one fundamental flaw in O\&R's theory still remains (from W's point of view): no unambiguous language can be described, as uncertainty is an inherent part of any culture. Inspired by this practice, the CLRU was torn between two opposing concepts in the 1950s, like most other AI groups:

1) The need to find a machine translation interlingua based on a set of linguistic primitives (semantic correspondences between languages);

2) The fact that words do not have a simple, precise meaning but are vague and rely on how they are used in language games (i.e. Depends on experience and, more generally, on context).

The first concept is the one that $\mathrm{W}$ advocates. The second in the Philosophical Investigations, in the Tractatus. This last place affected Masterman to a large extent. The value of the CLRU for semantic primitives, however, forming a kind of language game, is closer to the first rather than the second position. Y. Wilks (1939-), a former student of Masterman and the editor of a book gathering her most important works (Masterman, 2005) stresses that Masterman was highly influenced by the stick pictures of the language books, seen as a product of W's "forms of life" (Masterman, 2005, p. 215). Basic English can actually be seen as a practical experiment in W's language games (Masterman will also develop a similar approach to Ogden's, using Chinese characters as primitive rather than English words, under M.A.K's influence. Halliday (1925-), then a reader in Chinese in Cambridge). There is an apparent contradiction between a fixed, unambiguous theory of meaning and a fluid, situation-based alternative.

In a recent paper, Wilks indicates that if you postulate a non-logical yet realistic and empirical approach to semantum primitives, the paradox can be overcome. Primitives can be arranged as to form a word, he says, but this language remains vague, like every human language. Each primitive, however, 
subsumed sets of words from this language, thus forming a semi-formal language, halfway between human languages and formal approaches, particularly formal ontologies. We can obtain a consistent abstract representation of complex domains by stacking these representation levels. It is not clear if the problem can be solved by this approach. Wilks notes the internet is a sea of text and has been expanding without significant problems.

Wilks (2006) suggests that this "not so formal" approach can slowly formalize a number of applications and domains. The whole approach is based on the assumption that the language itself is the only way to design a language, leaving alone the distinction between formal and non-formal. Nevertheless, as primitives remain unknown in this method, no clear of this statement has been made so far.

\section{Conclusion}

In this article, we showed the dynamic network of influences of Wittgenstein, Ogden \& Richards, and recent AI research. We saw two contrasting directions: 1) the assumption that meaning and use of language are important and 2) the interest/need for semantic primitives regarded as a set of basic units which can be used as interlingua. This problem is still open today and no solution seems to have been proposed that would certainly fix it. It is therefore highly relevant to bear in mind historical research as highlighting recent discussions in the literature is highly valuable.

\section{References}

Antonius Waget, Violations of Grice's Maxims in The Prince and the Pauper Movie, LLT journal vol. 18, no. 1 ISSN 1410-7201

Diskriyanto, D. (2019). Achievement of Pragmatic Equivalence of the Grice's Cooperative Principle in the Indonesian Subtitle of Incredibles 2 Movie (Doctoral dissertation, UNNES).

Firth, J. R. (1961). Papers in Linguistics 1934-1951: Repr. Oxford University Press.

Guimarães, E., \& de Barros, D. L. P. (Eds.). (2007). History of Linguistics 2002: Selected Papers from the Ninth International Conference on the History of the Language Sciences, 27-30 August 2002, São Paulo-Campinas (Vol. 110). John Benjamins Publishing.

Léon, J. (2007). From Universal Languages to Intermediary Languages in Machine Translation The work of the Cambridge Language Research Unit (1955-1970). Amsterdam Studies in The Theory and History of Linguistic Science Series 3, 110,123 .

Lestari, N. G. (2019). An Analysis Of Flouting Maxims in Conversation Speaking of The Main
Character In The Movie of Home Alone 2 "Lost in New York" By John Hughes. Jurnal JOEPALLT (Journal of English Pedagogy, Linguistics, Literature, and Teaching), 7(1).

Monk R., 1991. Ludwig Wittgenstein: The Duty of Genius. London: Penguin. retrieved from Antonius Waget, Violations of Grice`s Maxims in The Prince and the Pauper Movie, LLT Journal Vol. 18, N0. 1 ISSN 1410-7201

Nuraini, L. (2019). An Analysis of Maxim Violations in Movie Confessions of a Shopaholic and Their Impacts on Effective Communication. ETD Unsyiah.

Ogden, C. K., \& Richards, I. A. (1923). The Meaning of Meaning: A Study of the Influence of Language upon Thought and of the Science of Symbolism (Vol. 29). K. Paul, Trench, Trubner \& Company, Limited.

Perzanowski, J. (1993). What is non-fregean in the semantics of Wittgenstein'sTractatus and why? Axiomathes, 4(3), 357-372.

Qassemi, M., Ziabari, R. S., \& Kheirabadi, R. (2018). Grice's Cooperative Principles in News Reports of Tehran Times-A Descriptive-Analytical Study. International Journal of English Language and Translation Studies, 6(1), 66-74.

Rahman, F. (2018). The Constraints of Foreign Learners in Reading English Literary Works: A Case Study at Hasanuddin University. Journal of Arts and Humanities, 7(2), 01-12.

Rahmi, S. S., Refnaldi, R., \& Wahyuni, D. (2018). The Violation of Conversational Maxims Found in Political Conversation at Rosi Talkshow. EJournal English Language and Literature, 7(1).

Sari, R., Putri, S. E., Herdi, H., \& Hamuddin, B. (2018). Bridging critical discourse analysis in media discourse studies. Indonesian EFL Journal, 4(2), 80-89.

Setiawan, F. A., \& Haryani, H. (2020). An Analysis of Maxim Flouting in Pokémon: Detective Pikachu Movie. PROJECT (Professional Journal of English Education), 3(2), 224-230.

Silitonga, I. C., Saragih, A., \& Pulungan, A. H. (2019). Lexical Metaphor in Novel and Film Critical Eleven.

Sunardi, S., Akil, M., Arafah, B., \& Salija, K. (2018). Looking at the Shared Conception of Teaching Literature in an Indonesian ELT Setting. Journal of Language Teaching and Research, 9(2), 316327.

Syam, A. T. (2019). The Analysis of System Constraints in National Treasure 2: Book of Secrets Movie. Language Circle: Journal of Language and Literature, 13(2). 
Waget, A. (2016). Violations of Grices maxims in The Prince and the Pauper movie. LLT Journal: A Journal on Language and Language Teaching, 18(1), 1-10.

Wahyuni, M., Arifin, M. B., \& Lubis, I. S. (2019). An analysis of flouting of maxims done by main characters in la la land movie. Jurnal Ilmu Budaya Vol, 3(3). 